\title{
Teaching Mode of Dance Appreciation Micro-course Based on Primary Teaching Theory
}

\author{
https://doi.org/10.3991/ijet.v13i08.9045 \\ Sanxia Yang \\ Hubei Communication Technical College, Wuhan, China \\ yangsanxia@yeah. net
}

\begin{abstract}
A dance appreciation course is set up in colleges to cultivate the aesthetic judgment of students and enhance their comprehensive accomplishment. However, in the traditional teaching mode, teachers are given insufficient time to deliver the contents of dance appreciation courses, thereby leading to some problems such as the fragmented knowledge structure of students and an ineffective course delivery. To address these problems, a new teaching mode called "micro-course" was designed in this paper based on primary teaching theory. By placing dance appreciation at its core, the micro-course teaching mode is divided into four stages, namely, activate old knowledge, demonstrate new knowledge, apply new knowledge, and digest. A "four-in-one" (creationteaching-performance-appreciation) dance micro-course was then designed followed by the construction of an online learning mode that is suitable for dance majors. Multiple experiments were also conducted to verify the effect and universality of this teaching mode and to provide a valuable reference for future studies on teaching public art courses.
\end{abstract}

Keywords-primary teaching theory; four-in-one; micro-course; dance appreciation

\section{$1 \quad$ Introduction}

Dance appreciation has been taught for a long time in colleges. This course aims to cultivate the aesthetic judgment of students and enhance their comprehensive accomplishment. As the concept of quality-oriented education has become popular nationwide, colleges have begun to focus more on the comprehensive development of their students. However, many colleges are still facing several challenges in teaching dance appreciation as described below:

1. Each student has a unique foundation for learning dance appreciation because of the differences in their living environments and interests. Therefore, these students also show differences in their learning of dance appreciation. Those students with a solid learning foundation feel that the knowledge they acquire through this course is insufficient, while those students with a poor learning foundation are having 
some difficulties in grasping course-related knowledge, thereby leading to a sharp decline in their learning efficiency [1].

2. Teachers are given insufficient time to deliver dance appreciation courses in the classroom. Dance appreciation is a public optional art course that has not received sufficient attention from colleges. As a consequence, many colleges have not integrated dance appreciation into their curriculum. Meanwhile, the lack of teaching re-sources in some colleges has greatly limited the number of students who can take up this course [2]. Therefore, some reforms must be implemented in teaching dance appreciation.

3. The independent inquiry ability of students cannot be enhanced. When teaching dance appreciation, the independent inquiry of students is as important as the guidance provided by their teachers. Students hope that their teachers can provide them with timely guidance and offer them with one-to-one tutoring. However, one teacher cannot teach his/her students individually, especially when handling large classes. Therefore, in the traditional teaching mode, teachers need to clarify the requirements of the learning task, decompose the knowledge points, demonstrate the operation, and let their students practice the operation for the second half of the period. However, in this manner, students are often unable to recall new moves. Such setup also prevents students from developing their independent inquiry ability [3] and cannot guarantee improvements in the teaching effect.

In this case, the mode for teaching dance appreciation must be reformed. Primary teaching theory takes a real problem case as its object to achieve the "3E (more effective, efficient, and engaging learning) teaching [4] effect" when implementing a solution to this problem. Given the proliferation of Internet and mobile technologies in the field of education, the idea of combining primary teaching theory with micro-courses has been received positively by numerous educators. Based on primary teaching theory, the "four-in-one" micro-course teaching method was proposed to cultivate the independent inquiry ability of students and to solve the problems related to the lack of teaching period and teaching resources.

\section{State of the art}

Art education is an indispensable part of higher education in China, and various art courses are being delivered throughout the country. To cultivate the independent inquiry ability of students and enhance their learning, several teachers have implemented a series of reforms in their teaching practices. For instance, Zhang [5] proposed the studio talent training mode, which can organically integrate classroom teaching, topic, and practice as well as enhance the conventional teaching method by using process teaching and practice teaching. Tong [6] proposed an interactive teaching mode for art based on the exchange of information and emotion between teachers and their students. In this teaching mode, the interactions between teachers and students as well as among students are considered the basic features of classroom teaching. This teaching mode also identifies the student as the core of teaching and highlights the importance of active learning and exchange in their learning process. However, this teaching 
mode requires a certain number of teaching staff. Meanwhile, Du [7] applied the selforganization teaching mode for teaching art that changes continuously based on the project requirements. Under this teaching mode, the students can move freely and are assigned roles that suit their demands and abilities. Based on this teaching method, the hackerspace teaching method was proposed to help art majors achieve innovation in their work and link their originalities to the market. Accordingly, this method has become an important tool for assisting teachers and students in art colleges. To improve the inquiry ability of students, Sen [8] proposed a customized education and individualized teaching method based on the new Education Plan of British Columbia that places individualized learning at its core. Sen also discussed the genealogy of this Education Plan and its meanings for public education in the province, constructed a network of actors, and analyzed the contents of important documents produced by public and private sectors to prove that this teaching method could enhance the inquiry ability of students to a certain degree. Yakhforoshha [9] integrated the essential features of simulation and art to develop the Integrated Model for Communication Skills (IMCS) education. By reviewing the literature on medical education and by constructing a simulation model and main framework for teaching art, Yakhforosha found that IMCS integrates the three concepts of the Jeffries simulation model, namely, simulation design, simulation intervention, and outcome. This model also adopted activity theory and transformative learning theory to foster the skill- and emotionbased communication skills of students.

The application of the micro-course teaching method has demonstrated some progress in China and in some foreign countries. However, China still lacks all-around and general course design models. In this paper, the teaching content of dance appreciation course was reformed based on primary teaching theory, the requirements of the "four-in-one" principles (creation-teaching-performance-appreciation), the micro-course teaching mode, and the advantages of short-time and efficient multimedia information to provide references for reforming the teaching of other art courses.

\section{3 "Four-in-one" teaching mode based on primary teaching theory}

The primary teaching theory proposed by Merril mainly regards practical problem solving as the central task in the teaching process and takes "focus on solving problems," "activate old knowledge," "demonstrate new knowledge," "try application," and "digest" as the five elements of primary teaching theory as shown in Fig. 1.

These five elements can be integrated into dance appreciation as follows. Before delivering the course contents, teachers must propose several tasks that comply with their teaching objective and the knowledge reserve and age features of their students. This process is shown in Fig. 2. In the teaching process, the original knowledge of students and their experiences related to each chapter of the dance course can be activated, and such knowledge may serve as the foundation for teaching the next chapter. A vivid dance course design simulation technology may be used along with computer and multimedia to develop a suitable dance model that can help students understand 
the key knowledge points of the course. These students must also apply the knowledge that they have learned to solve a dance appreciation task under the guidance and feedback of their teachers. When students are faced with a new appreciation task, they can refer to what they have previously learned and then adjust, modify, and transform such knowledge. In general, primary teaching theory requires the learning process to focus on the problem-solving process. Teachers must evaluate, guide, and promote each link when students are solving a dance appreciation task and then modify their teaching content to adapt to the needs of their students.
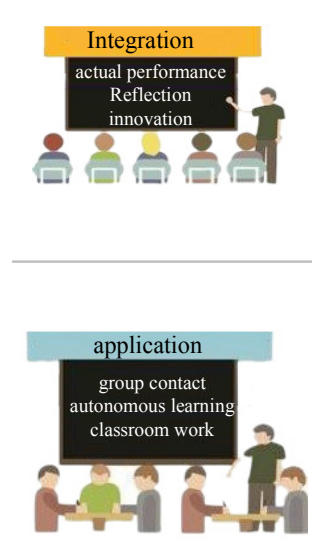

Fig. 1. Five core elements or principles of primary teaching theory

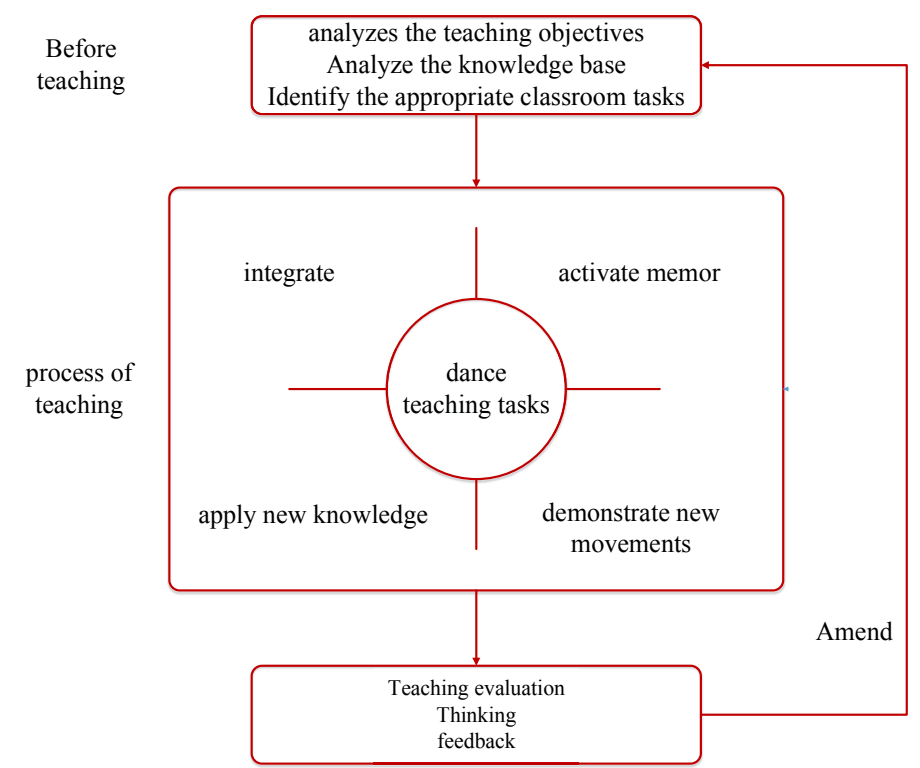

Fig. 2. Teaching mode based on the five core elements or principles of primary teaching theory 
While promoting dance appreciation in colleges, teachers must be given a sufficient time to deliver the course contents and students must be able to develop their comprehensive knowledge of dance appreciation within a limited time. Micro-course is a teaching form that can be used to solve such challenges. As the first to introduce such concept in China, Hu defined "micro-course" as a teaching mode that has emerged as a result of the rapid development of multimedia and information technology. This teaching mode allows students to maximize their use of the Internet for their studies. Teachers transform a knowledge point of a course into a short teaching video and then improve this video to create a new teaching resource to replace the traditional classroom teaching mode. In this teaching mode, students can utilize their free time to learn new knowledge and appreciate dance at any time and place, thereby effectively addressing the problems faced by teachers with regard to their limited teaching time under the traditional teaching mode. Micro-course also helps students fully utilize their time and reduce their learning pressure. Videos or certain multimedia software can also bring diversified learning methods for students. In dance appreciation, micro-courses can transform dance-related knowledge into videos that can be understood more vividly by students compared with the direct explanation of their teachers. The micro-course design and development process is shown in Fig. 3.

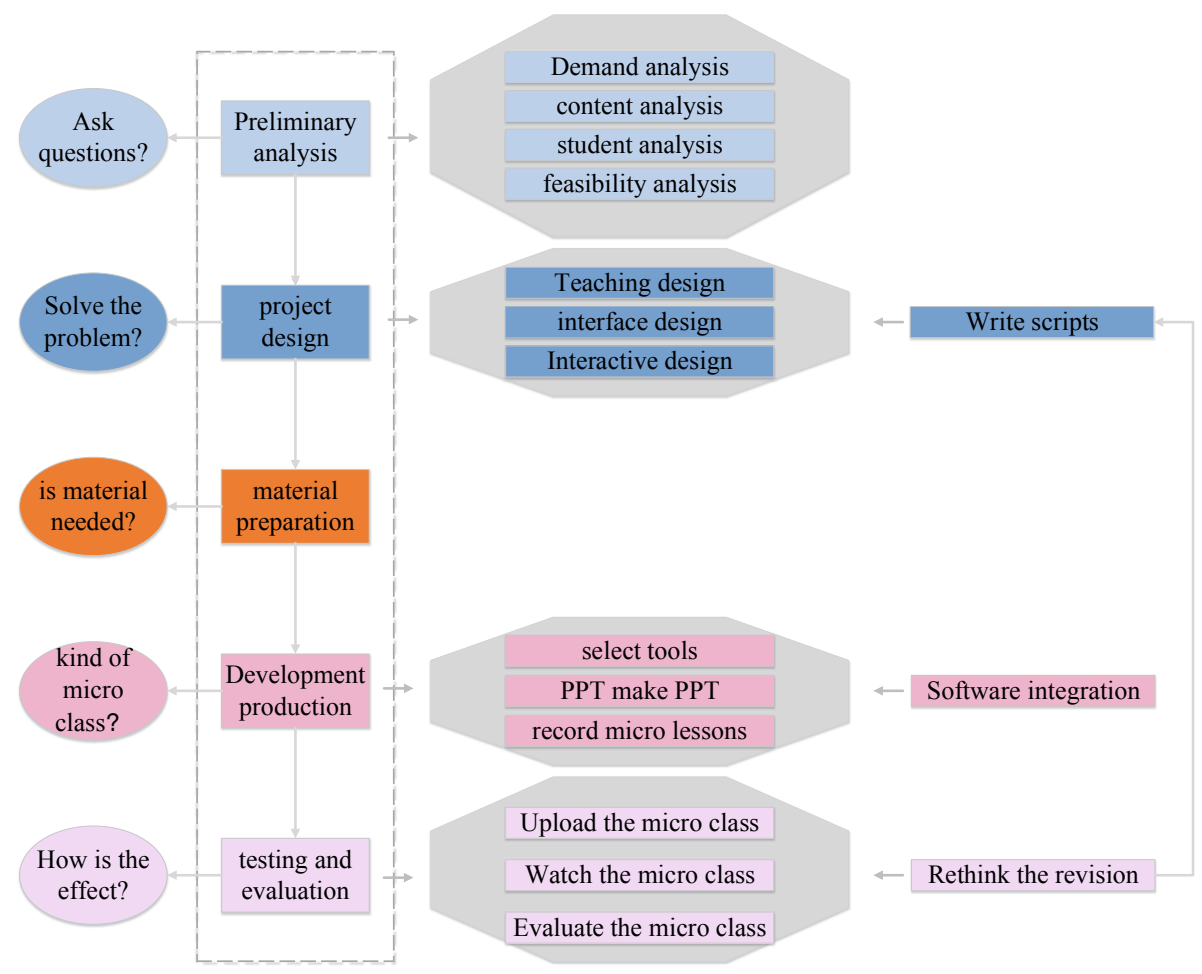

Fig. 3. Micro-course design and development process 
A dance appreciation course must embody the "four-in-one" (creation-teachingperformance-appreciation) principle of art courses. In other words, dance appreciation must not only focus on dance education but also cultivate the dance creation abilities and performance of students. In each chapter of the dance appreciation course, the students act as the dominators, creators, performers, and reviewers. Therefore, teachers must guarantee the full combination of theory and practice in their teaching modes. A dance appreciation micro-course teaching mode was then designed in this paper based on primary teaching theory.

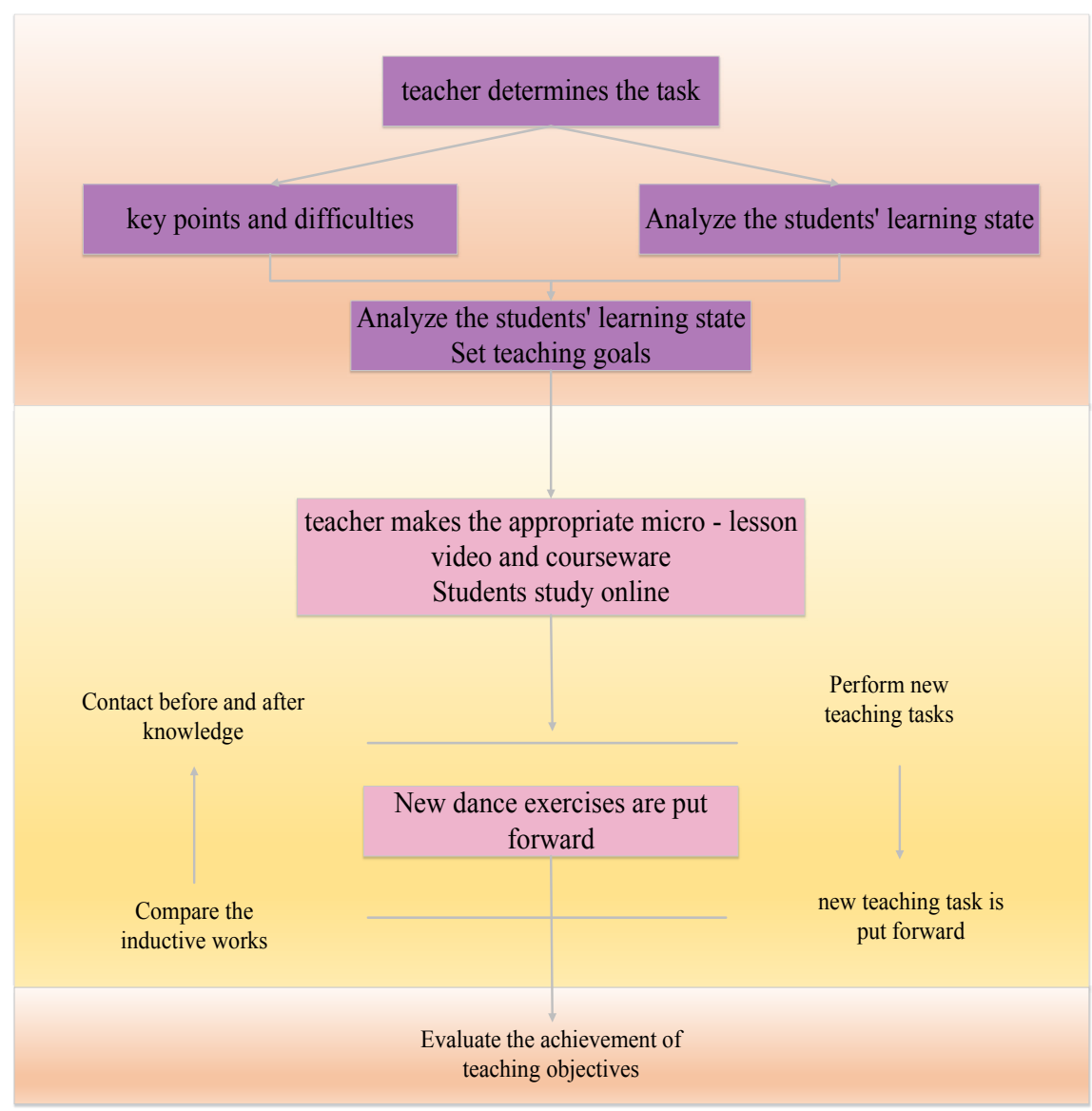

Fig. 4. Micro-course teaching mode design based on primary teaching theory

Before delivering the course contents, teachers must make sufficient preparations, know their teaching objective, analyze the most important and difficult points of the course, determine their professional knowledge level, and identify the expected effects of the course on the learning of their students. Afterward, they must create a micro-course content file by screening, editing, and supplementing relevant electronic videos into short videos that include knowledge points related to dance and cover 
high-level and appreciative dance programs to enhance the interest of students toward dance appreciation. They must also propose suitable dance appreciation tasks and let their students create, gather, or synthesize their knowledge into new dance appreciation activities. While solving their learning tasks, students must utilize their learned or original dance appreciation knowledge and then apply such knowledge to their dance performance, creation, evaluation, analysis, and appreciation through comparison, conclusion, summarization, and deduction. The learning situations and structures of these students must also be fed back to the teachers in time. Afterward, the teachers must adjust and modify their objective or tasks according to specific conditions and then feed them back to their students. This teaching mode is summarized in Fig. 4.

\section{$4 \quad$ Teaching example and teaching effect}

\subsection{Teaching example}

Before implementing any teaching mode, the teaching objective must be confirmed. Given that dance appreciation aims to cultivate the art appreciation of students, teachers must ask their students to analyze several aspects of the dance performance process, including pace grasp, dynamic aesthetic feeling, picture composition display, and emotional expression. Teachers can refer to the "four-in-one" dance teaching mode to hone the comprehensive dance skills and quality of their students. Generally, the contents of the dance appreciation course must include dance system learning, dance feeling appreciation, dance performance, and dance improvement. Moreover, in the learning process, teachers must facilitate a cooperation among their students and regularly interact with them to promote an all-around participation. As shown in Fig. 5, the learning process must also involve viewing, thinking, observing, appreciating, practicing, moving, showing emotions, commenting, explaining, and creating.

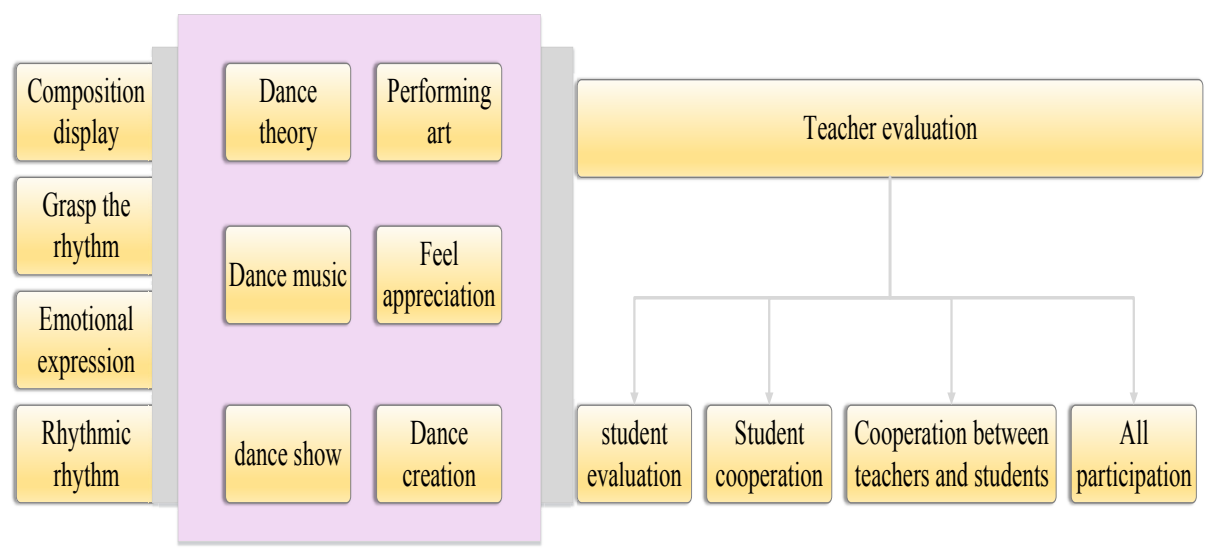

Fig. 5. Content diagram of the "four-in-one" teaching mode for dance appreciation 
Teachers must screen the contents of each chapter of the micro-course and analyze the details of the course implementation. They must also set the key points in the implementation of this course according to the contents of each chapter.

In this paper, the 90-minute dance drama, The Peony Pavilion, was used for teaching dance appreciation. The implementation flow was designed according to the frame in Fig. 4, and further details can be found in Figs. 6 and 7. Before attending their class, the teachers condensed their prepared dance knowledge points into six micro-course videos by combining each fragment of the drama, uploading them to the campus information network resource platform, and asking their students to view these videos. Afterward, the students were asked to watch and understand the contents of the adapted dance drama, The Peach Blossom Fan. The teachers then started interacting with their students by asking them to report the knowledge contents of this play and propose relevant contents. After the reporting, the teachers guided the learning of their students and answered their questions. After the class, the students were required to test the contents of the course chapter, while the teacher guided their students to help deepen their knowledge. The theoretical knowledge and practice of the dance drama were constantly involved in these processes. The task of "dance drama adaption conception" can help students discover problems in dance appreciation. While solving this task, the students can also acquire basic dance knowledge and hone their art appreciation ability.

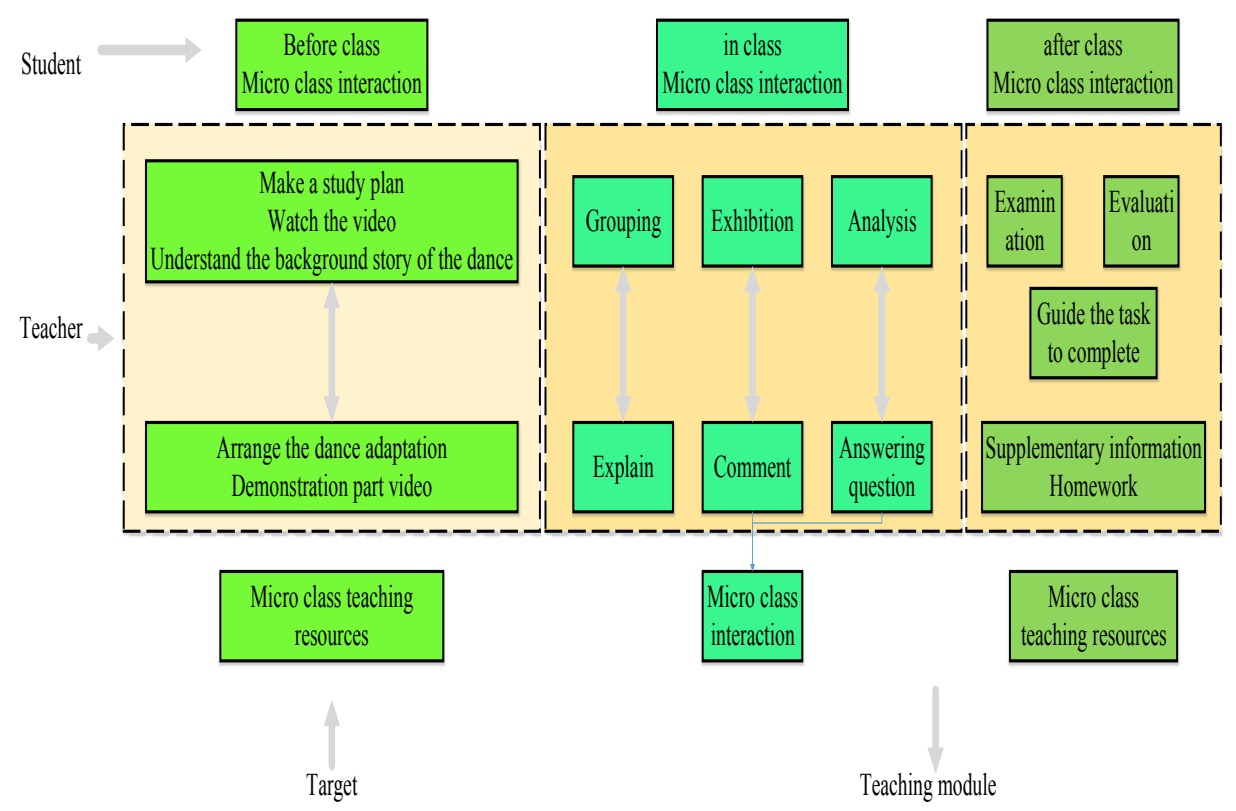

Fig. 6. Implementation process diagram of dance drama appreciation 
Paper-Teaching Mode of Dance Appreciation Micro-course Based on Primary Teaching Theory

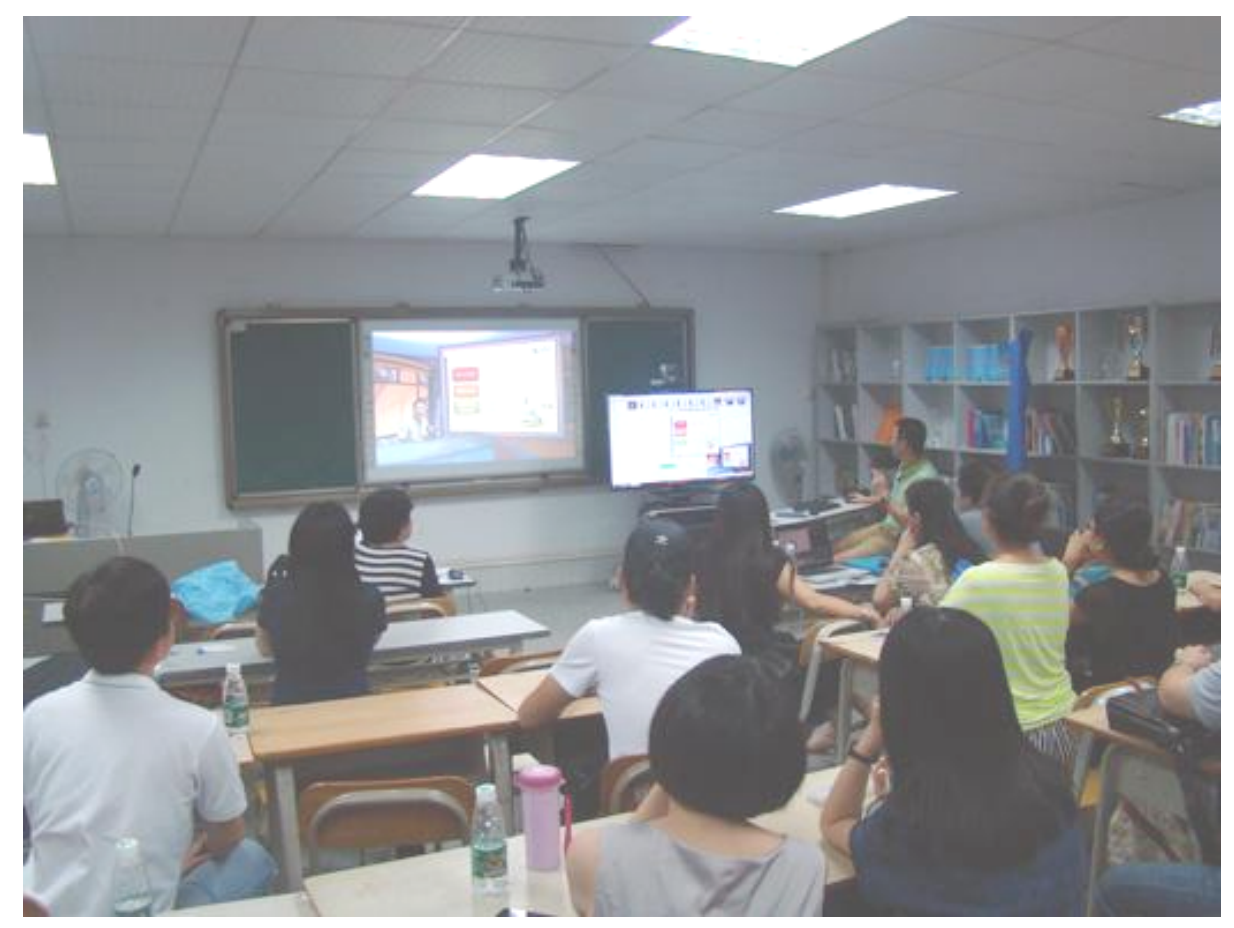

Fig. 7. Teachers conduct micro-course production exchanges and discussions

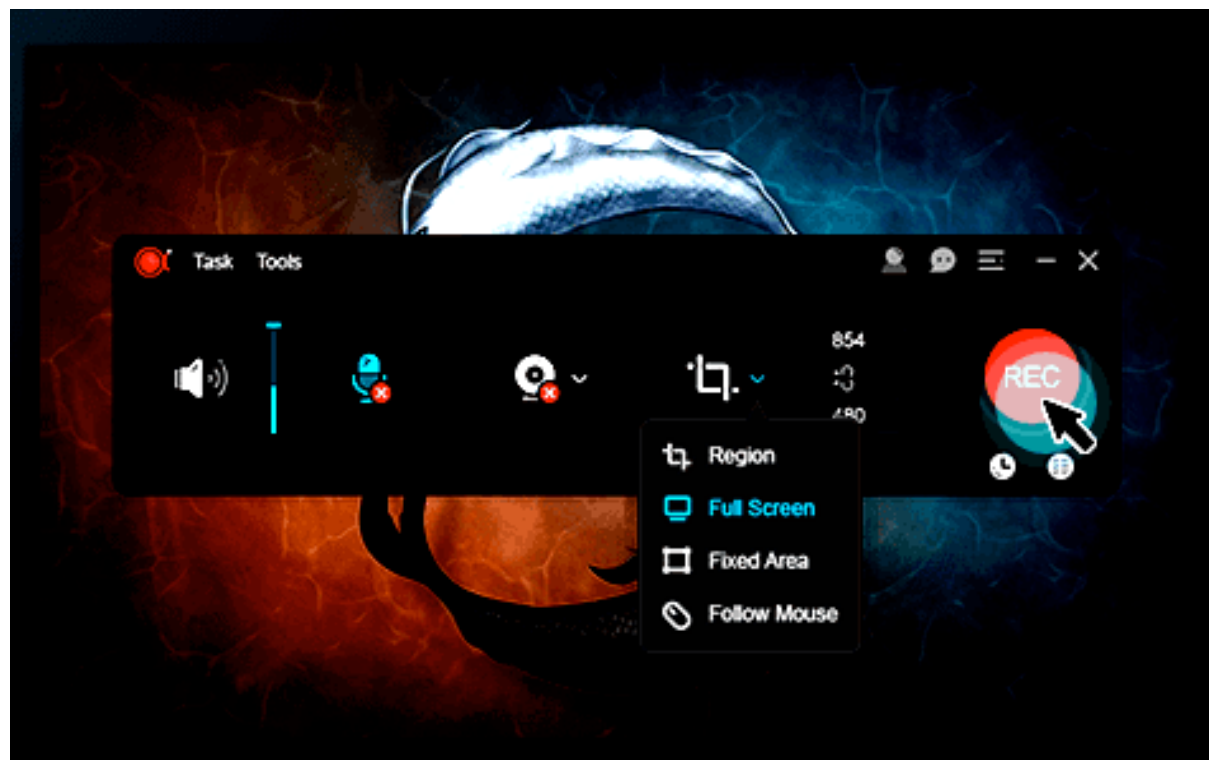

Fig. 8. Production steps (1) 


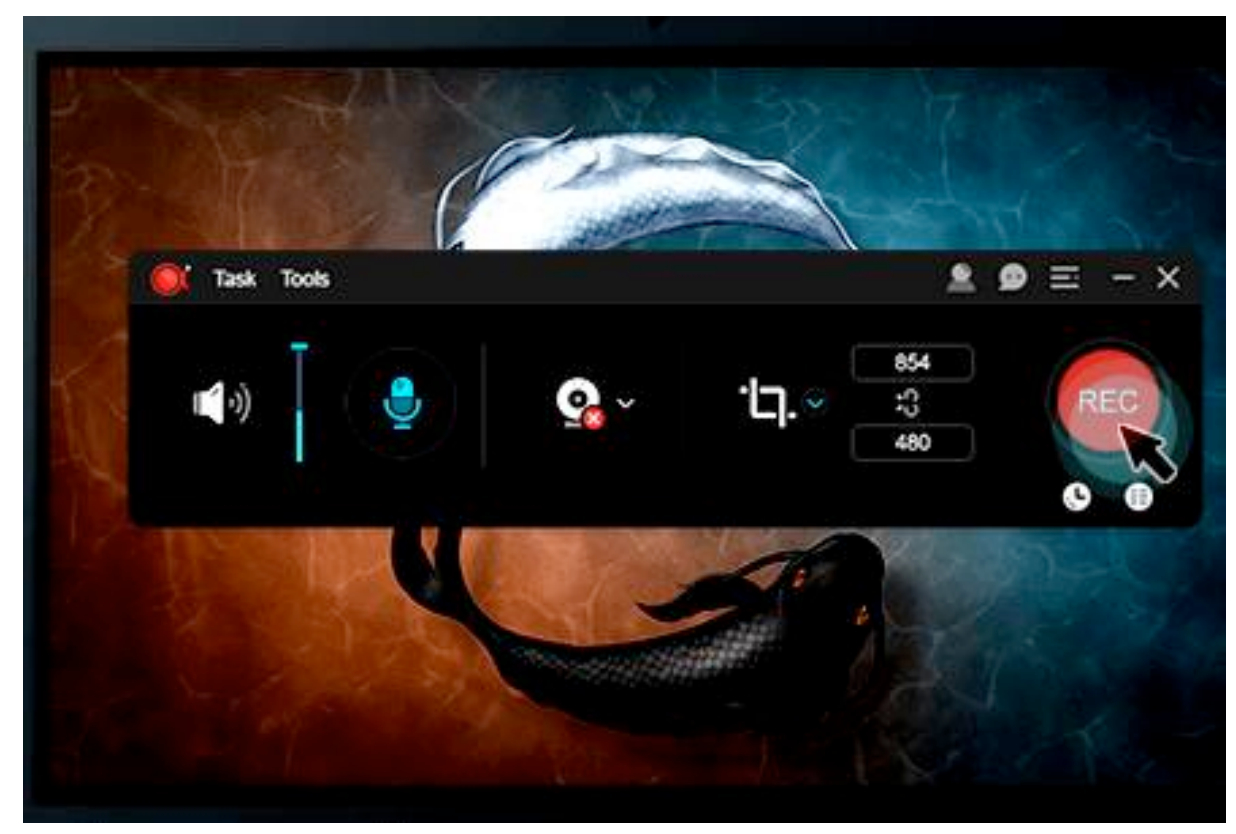

Fig. 9. Production steps (2)

\subsection{Teaching effect}

The dance appreciation course of the Hubei University of Arts and Sciences was selected to test the teaching effect of the proposed teaching mode. This course was divided into 16 chapters. One chapter was implemented for an experimental class and a traditional parallel class via the micro-course teaching mode based on primary theory and the traditional teaching mode, respectively. Classroom PPT teaching was initially performed. Afterward, the students were required to appreciate The Peach Blossom Fan, and both of these classes were required to submit a report afterward.

A written test was then conducted to check the theoretical knowledge and evaluate the appreciation of the students from both classes. The test scores of both classes were then gathered and summarized in Table 1.

Table 1. Comparison of test scores

\begin{tabular}{cccccc}
\hline Class & No & Scores & Excellent ratio & $\boldsymbol{t}$ & $\boldsymbol{P}$ \\
\hline Experimental class & 203 & $82.36 \pm 5.35$ & $15 \%$ & 4.862 & $<0.001$ \\
Control class & 209 & $78.85 \pm 12.26$ & $8 \%$ & & \\
\hline
\end{tabular}

Table 1 shows that the test results of the experimental class is slightly superior to that of the traditional parallel class. A further analysis reveals that the autonomous learning interest of the students greatly improved under the proposed teaching mode. In each link of before-class, in-class, and after-class, the students were required to 
fully understand the theoretical knowledge in order to solve their task and to deepen their theoretical knowledge of the course chapter. These students acquired new knowledge while solving practical problems and utilized specific application schemes and conditions to understand the course contents thoroughly.

After the test, five teachers implemented the proposed teaching mode in the succeeding chapters of the dance appreciation course. After each semester, these teachers evaluated the effect of the proposed teaching mode by filling out a multiple choice questionnaire. The results are shown in Table 2.

Table 2. Evaluation of teachers regarding the teaching effect of the proposed micro-course teaching mode

\begin{tabular}{|l|c|c|c|}
\hline \multicolumn{1}{|c|}{ Advantages } & Yes & Intermediate & No \\
\hline Innovates the teaching effect of dance appreciation & $5(100 \%)$ & 0 & 0 \\
\hline $\begin{array}{l}\text { Highlights the professional knowledge of teachers about dance appre- } \\
\text { ciation }\end{array}$ & $3(60 \%)$ & $2(40 \%)$ & 0 \\
\hline Improves the teaching effect of dance appreciation & $4(80 \%)$ & $1(20 \%)$ & 0 \\
\hline Enhances the art appreciation level of students & $4(80 \%)$ & 0 & $1(20 \%)$ \\
\hline Promotes the comprehensive art quality of students & $3(60 \%)$ & $2(40 \%)$ & 0 \\
\hline Motivates the art appreciation interest of students & $5(100 \%)$ & 0 & 0 \\
\hline Enhances the interaction initiative of students & $4(80 \%)$ & $2(40 \%)$ & 0 \\
\hline Expands as a teaching method & $5(100 \%)$ & 0 & 0 \\
\hline
\end{tabular}

All teachers confirmed the advantages of the proposed teaching mode after its application for one semester. Around $80 \%$ to $100 \%$ of these teachers argued that this teaching mode not only innovates the teaching effect but also highlights their professional knowledge of dance appreciation, improves their teaching effect, motivates the interest of their students, and improves classroom interactions. This teaching mode also significantly improves the practical application abilities and test scores of their students compared with the traditional teaching mode. When these students learned in groups, they demonstrated improvements in their learning interest and avoided mental stress when faced with dull and difficult knowledge during the cooperation process. While solving each appreciation task, the students applied all their relevant knowledge, including their old and new knowledge, knowledge learned in and outside class, and aesthetic, literature, and music knowledge. In this way, these students were not forced to show improvements in their aesthetic judgment. The comprehensive quality of these students was also improved. However, some teachers shared that the proposed teaching mode might restrict their students to task solving and did not take into account the knowledge points listed in the dance appreciation course, thereby limiting their appreciation level. To address this problem, the micro-course teaching mode needs to impose higher requirements for teachers. Specifically, these teachers must possess a high level of professional theoretical knowledge to ensure their allaround understanding of dance appreciation. 


\section{Conclusions}

While promoting dance appreciation as a public art appreciation course among colleges, the traditional teaching mode was deemed ineffective given the insufficient time allotted to teachers to deliver the course contents. As a result, their students gradually lost their interest in learning, which in turn significantly influenced the teaching effect of their teachers. The micro-course teaching mode based on primary theory was then proposed according to the "four-in-one" dance teaching mode. Such teaching mode made up for the disadvantages of the traditional teaching mode and ensured a positive teaching effect by using an online teaching platform. The advantages of this teaching mode include the following:

1. The experiment proved that the "four-in-one" micro-course teaching mode based on primary teaching theory can help students learn and improve their learning efficiency within a limited time. This teaching mode not only makes up for the limitations of the traditional teaching mode but also cultivates the positive learning habits of students and helps teachers achieve their teaching objectives.

2. The dance appreciation learning process can help students improve their repetition and utilization of relevant knowledge, facilitate their deep learning of new knowledge, and enhance their independent inquiry ability.

3. Through the proposed teaching mode, the students can apply knowledge hierarchy in their problem-solving tasks and consequently show improvements in their art appreciation ability and comprehensive accomplishments. The proposed method can also cultivate the high-quality talent of art majors.

\section{References}

[1] Hu, Y.L. Study on Identification and Enjoyment of Dance Evaluation and Appreciation of Public Arts Course in Colleges and Universities. Journal of Changzhou College of Information Technology, 2017, vol. 16(3), pp. 29-31.

[2] Stark, K.K. Connecting to Dance: Merging Theory with Practice. Journal of Dance Education, 2009, vol. 9(2), pp. 61-68. https://doi.org/10.1080/15290824.2009.10387387

[3] Sun, L., Liu, C., Yang, W., et al. Enhancing Theory of Mind through Dance Appreciation. Psychology Techniques \& Applications, 2017, vol. 5(3), pp. 138-145.

[4] Merrill, M.D. Finding e3 (effective, efficient, and engaging) instruction. Educational Technology the Magazine for Managers of Change in Education, 2009, vol. 49(3), pp. 1526.

[5] Zhang, X.Y. Application of Studio-based Teaching Model in Art Design Teaching in Colleges and Universities. Big stage, 2014, vol. 12, pp. 217-218.

[6] Tong, L. Construction and Practice of Interactive Teaching Mode in the Subject of Art Design. Global Education, 2012, vol. 26(3), pp. 83-86.

[7] Du, H.M., Zhang, S.M. Discussion on Teaching Mode of Overturning Class Based on Self-organization Theory. Art Education Research, 2015, vol. 13, pp. 134-136.

[8] Sen, V. Towards Customized Privatization in Public Education in British Columbia: The Provincial Education Plan and Personalized Learning. Canadian Journal of Educational Administration \& Policy, 2017, vol. 180, pp. 135-168. 
Paper-Teaching Mode of Dance Appreciation Micro-course Based on Primary Teaching Theory

[9] Yakhforoshha, A., Emami, D.S.A.H., Mohammadi, N., et al. Developing an integrated educational simulation model by considering art approach: Teaching Empathic Communication skills. Europan Journal for Person Centered Healthcare, 2017, vol. 5(1), pp. 154-165. https://doi.org/10.5750/ejpch.v5i1.1299

[10] Kilic, A. Learner-Centered Micro Teaching in Teacher Education. Online Submission, 2010, vol. 3(1), pp. 77-100.

[11] Saban, A., Coklar, A.N. Pre-Service Teachers' Opinions about the Micro-Teaching Method in Teaching Practise Classes. Turkish Online Journal of Educational Technology, 2013, vol. 12(2), pp. 234-240.

\section{$7 \quad$ Authors}

Sanxia Yang is an associate professor in the Hubei Communication Technical College, Wuhan 430079, China (yangsanxia@yeah.net).

Article submitted 16 March 2018. Resubmitted 27 June 2018. Final acceptance 13 July 2018. Final version published as submitted by the author. 